PHARMACONJurnal IImiah Farmasi - UNSRAT Vol. 9 No. 1 FEBRUARI 2020 ISSN $2302-2493$

\title{
PENGUKURAN KINERJA INSTALASI FARMASI RUMAH SAKIT DAERAH LIUN KENDAGE TAHUNA DENGAN METODE BALANCED SCORECARD
}

\author{
Mariana Cristi Ayu Gagola ${ }^{1)}$, Gayatri Citraningtyas ${ }^{1)}$, Imam Jayanto ${ }^{1)}$ \\ ${ }^{1)}$ Program Studi Farmasi FMIPA UNSRAT Manado, 95115
}

\begin{abstract}
IFRS (Hospital Pharmacy Installation) has a strategic role in the development and economy of the hospital, so it is necessary to measure performance using the Balanced Scorecard (BSC) method. Research with BSC is to determine the performance of IFRS Liun Kendage Hospital, Tahuna, which is reviewed from a perspective of financial, and internal business process. This research is descriptive with retrospective and prospective data collection obtained through observations, administrative and financial reports of IFRS of Liun Kendage Hospital, Tahuna. The results showed that performance in the 2018 financial perspective contributed IFRS to the Hospital 34.34\%, ITOR 3.99 times, internal business process perspective was obtained from the availability of drugs $89 \%$, drug information services did not meet the 2016 Kepmenkes standard, dispensing time for concoctions, 39.48 minutes and non-concoction 28.45 minutes. The conclusion that the IFRS performance of Liun Kendage Hospital, Tahuna using the BSC method with two perspectives shows a pretty good performance. But there still needs to be an improvement in dispensing time, controlling drug supplies and drug information services.
\end{abstract}

Keywords: Pharmacy Installation, Performance, Balanced Scorecard

\begin{abstract}
ABSTRAK
IFRS (Instalasi Farmasi Rumah Sakit) memiliki peran yang strategis dalam perkembangan serta ekonomi rumah sakit, perihal tersebut sehingga perlu dilakukan pengukuran kinerja dengan metode Balanced Scorecard (BSC). Penelitian dengan BSC untuk mengetahui kinerja IFRS Liun Kendage Tahuna yang ditinjau dari perspektif keuangan dan perspektif proses bisnis internal. Penelitian ini bersifat deskriptif dengan pengambilan data secara retrospektif dan prospektif yang diperoleh melalui observasi, laporan administrasi dan keuangan IFRS dan Rumah Sakit Liun Kendage Tahuna. Hasil penelitian menunjukkan bahwa kinerja pada perspektif keuangan tahun 2018 kontribusi IFRS ke RS 34,34 \%, ITOR 3,99 kali, perspektif proses bisnis internal didapatkan dari ketersediaan obat 89\%, pelayanan informasi obat belum memenuhi standar Kepmenkes 2016, dispensing time untuk racikan 39,48 menit dan non racikan 28,45 menit. Kesimpulan yang didapat bahwa kinerja IFRS Liun Kendage Tahuna yang menggunakan metode $B S C$ dengan dua perspektif menunjukkan kinerja yang cukup baik. Tetapi masih perlu adanya perbaikan dalam dispensing time, pengendalian persediaan obat dan pelayanan informasi obat.
\end{abstract}

Kata Kunci: Instalasi Farmasi, Kinerja, Balanced Scorecard. 
PHARMACONJurnal IImiah Farmasi - UNSRAT Vol. 9 No. 1 FEBRUARI 2020 ISSN $2302-2493$

\section{PENDAHULUAN}

Instalasi Farmasi Rumah Sakit (IFRS) dituntut untuk mampu mewujudkan kinerja yang baik dengan cara peningkatan keselamatan pasien. Cara yang ditempuh untuk mendapatkan hal yang dimaksud adalah melalui peningkatan kualitas klinis dan kinerja keuangan. Peningkatan kualitas pelayanan kesehatan sangat dipengaruhi oleh tersedianya sarana dan prasarana serta ketersediaan dana (Siregar dan Amalia, 2003). Pelayanan pasien selalu berkaitan dengan kinerja. Kinerja merupakan gambaran mengenai tingkat pencapaian pelaksanaan suatu kebijakan dalam mewujudkan sasaran, tujuan, visi dan misi organisasi yang tertuang dalam strategi organisasi (Liando et al., 2014).

BSC (Balanced Scorecard) adalah metode pengukuran kinerja yang memberikan gambaran keberhasilan dari perspektif keuangan, perspektif proses bisnis internal, perspektif customer serta perspektif pembelajaran dan pertumbuhan. Hasil dari pengukuran BSC digunakan sebagai dasar evaluasi terhadap pelayanan sehingga dapat memperbaiki kinerja demi pencapaian tujuan di masa yang akan datang (Mahmudi, 2005). Evaluasi, dengan metode $B S C$ tidak hanya berorientasi pada bidang administrasi dan sarana/prasarana tetapi juga sumber daya manusia (Rikomah, 2017). Rumah Sakit Daerah Liun Kendage Tahuna aktif dan bergerak melakukan penataan dan pengembangan disemua hal, termasuk pelayanan pasien di IFRS. Metode pengukuran BSC belum pernah dijabarkan di Rumah Sakit Daerah Liun Kendage Tahuna sehingga perlu diimplementasikan.

\section{METODOLOGI PENELITIAN}

Tempat dan Waktu Penelitian

Penelitian ini dilakukan pada bulan April-September 2019 di Instalasi Farmasi Rumah Sakit Liun Kendage Tahuna.

\section{Jenis dan Rancangan Penelitian}

Penelitian ini bersifat deskriptif dengan menggunankan metode retrospektif dan prospektif.

\section{Populasi dan Sampel Penelitian}

Perspektif keuangan hanya mengambil data keuangan IFRS \& RS tahun 2018. Populasi dalam penelitian perspektif proses bisnis internal, yaitu semua resep pasien IFRS Liun Kendage Tahuna. Sampel pada penelitian ini untuk perspektif proses bisnis internal yaitu lembar resep obat pasien rawat jalan umum dan BPJS IFRS Liun Kendage Tahuna, secara prospektif dengan purposive sampling menggunakan rumus slovin :

$$
\begin{gathered}
n=\frac{N}{1+N e^{2}} \\
n=\frac{6023}{1+(6023 \times 0,01)} \\
=\frac{6023}{61,23} \\
=98,3 \approx 100
\end{gathered}
$$

Keterangan :

$n=$ Ukuran Sampel

$\mathrm{N}=$ Ukuran Populasi

$\mathrm{e}=$ Persentase Kelonggaran

ketelitian karena kesalahan pengambilan sampel dan dapat ditolerir yaitu $10 \%, \mathrm{e}^{2}(0,01)$

(Riduwan, 2005) 


\section{Pengumpulan data}

Data yang diambil dalam penelitian ini berupa data kuantitatif :

1. Untuk perspektif keuangan, yaitu data laporan administrasi keuangan IFRS dan Rumah Sakit Liun Kendage Tahuna tahun 2018. Pada data tersebut dilakukan juga penghitungan untuk mengetahui kontribusi IFRS ke rumah sakit, ITOR dan average age of inventory.

2. Untuk perspektif proses bisnis internal, yaitu data yang diperoleh melalui observasi langsung proses pelayanan resep yang meliputi ratarata waktu dispensing time (racikan dan non-racikan), pemberian informasi obat, tingkat ketersediaan obat.

\section{Analisis Data}

Data yang telah terkumpul diolah dengan menggunakan perhitungan, dibandingkan dengan standar yang ada dan disajikan dalam bentuk tabel frekuensi dan persentase (Satibi et al., 2011).

\section{HASIL DAN PEMBAHASAN \\ 1. Perspektif Keuangan}

Dapat dilihat dalam perspektif keuangan dengan indikator Inventory Turn Over Ratio (ITOR), average age of inventory dan kontribusi IFRS terhadap rumah sakit.

Dari tabel I terlihat bahwa kontribusi IFRS ke Rumah Sakit Liun Kendage Tahuna sebanyak 34,34\%. Nilai ini menunjukkan bahwa cukup besarnya kontribusi IFRS ke rumah sakit. Instalasi Farmasi Rumah Sakit Liun Kendage Tahuna mempunyai nilai ITOR 3,99 kali pertahun. ITOR menunjukkan berapa kali nilai persediaan farmasi (obat, alat kesehatan, bahan medis habis pakai, reagen dll) berputar dalam satu tahun. Kondisi ITOR di IFRS Liun Kendage Tahuna dinilai masih kurang, yang menunjukkan belum efisiennya pengelolaan obat. Nilai ITOR untuk IFRS adalah 8-12 kali dalam pertahun. Hal ini diperkuat dengan ratarata penyimpanan persediaan (average age of inventory) yang lebih dari 30 hari, sehingga kemungkinan terjadinya penumpukan persediaan farmasi di gudang. Hasil menunjukkan untuk perspektif keuangan masih kurang, perlu adanya pengendalian persediaan agar perputaran persediaan lebih cepat dan tidak terjadi penumpukan barang digudang karena stok yang berlebih juga akan meningkatkan kerugian karena kerusakan perbekalan farmasi sehingga akan berdanpak terhadap peningkatan kontribusi IFRS ke rumah sakit.

Tabel 1. Rasio Kinerja Keuangan

\begin{tabular}{lc}
\hline \multicolumn{1}{c}{ Rasio } & Tahun 2018 \\
\hline Kontribusi IFRS ke Rumah Sakit Liun Kendage & $34,34 \%$ \\
Tahuna (\%) & 3,99 \\
ITOR (kali) & 91,31 \\
Average age of inventory (hari) & \\
\hline
\end{tabular}




\section{Perspektif Proses Bisnis Internal}

Berdasarkan hasil data yang telah diperoleh, didapatkan hasil sebagai berikut:

\section{a. Tingkat Ketersediaan Obat}

Persentase ketersediaan obat dihitung dari perbandingan jumlah item obat yang diserahkan dengan total item obat yang diresepkan masuk ke IFRS. Jumlah sampel resep yang diperoleh sebanyak 100 lembar dari 100 pasien. Persentase ketersediaan obat di IFRS Liun Kendage Tahuna dapat dilihat pada Tabel 2.

Tabel 2 menunjukkan jumlah item obat yang tersedia di IFRS sebesar 116 dari 130 total item obat yang diresepkan, sehingga persentase yang didapat IFRS
Liun Kendage Tahuna sebesar $89 \%$ yang berarti ada $11 \%$ obat yang tidak tersedia di IFRS yang disebabkan tidak terdeteksi obat yang hampir habis untuk obat yang jarang diresepkan, obat tersebut memang tidak tersedia/tidak pernah ada di IFRS. Perlu adanya pengendalian persediaan barang dengan melakukan penyeimbangan antara besarnya persediaan dengan besarnya permintaan sehingga IFRS dapat memenuhi kebutuhan oabt pasien, tetapi tidak mengalami kerugian.

Keseimbangan antara permintaan dan persediaan yang artinya persediaan lengkap/unitnya cukup tetapi tidak berlebihan (Satibi et al., 2011).

Tabel 2. Ketersediaan Obat pada Lembar Resep

\begin{tabular}{cccc}
\hline $\begin{array}{c}\text { Jumlah Total } \\
\text { Item Obat }\end{array}$ & $\begin{array}{c}\text { Jumlah Item } \\
\text { Obat Kosong }\end{array}$ & $\begin{array}{c}\text { Jumlah Item } \\
\text { Obat yang } \\
\text { Tersedia }\end{array}$ & $\begin{array}{c}\text { Tingkat } \\
\text { Ketersediaan } \\
\text { Obat (\%) }\end{array}$ \\
\hline 130 & 14 & 116 & 89 \\
\hline
\end{tabular}

b. Rata-rata Waktu Penyediaan Obat (Average Dispensing Time)

Pengukuran rata-rata waktu penyediaan obat dilakukan dari awal pasien menyerahkan resep sampai dengan pasien menerima obat beserta informasi penggunaan obat. Hasilnya dapat dilihat pada Tabel 3.

Tabel 3. Rata-rata Waktu Penyediaan Obat

\begin{tabular}{lccc}
\hline $\begin{array}{l}\text { Jenis obat } \\
\text { (total waktu } \\
\text { dalam menit) }\end{array}$ & $\begin{array}{c}\text { Penerimaan } \\
\text { resep }\end{array}$ & $\begin{array}{c}\text { Ruang } \\
\text { dispensing/racik }\end{array}$ & $\begin{array}{c}\text { Penyerahan } \\
\text { Obat }\end{array}$ \\
\cline { 2 - 4 } & 09,08 & 18,52 & 11,50 \\
\hline Racikan $(39,48)$ & 09,57 & 11,19 & 08,19 \\
$\begin{array}{l}\text { Non-racikan } \\
(28,45)\end{array}$ & & & \\
\hline
\end{tabular}

Proses penerimaan resep, dispensing/ racik sampai penyerahan resep di IFRS
Liun Kendage Tahuna dapat dideskripsikan sebagai berikut: 
a. Bagian penerimaan resep, untuk racikan dengan rata-rata waktu 9 menit 8 detik sedangkan untuk nonracikan dengan waktu 9 menit 57 detik. Hal-hal yang dilakukan pada bagian ini adalah:

1. Petugas memeriksa kelengkapan resep

2. Pasien diberikan nomor antri dan dibuat etiket

3. Jika ada resep yang tidak tersedia, dibuatkan copy resep

4. Resep diberi harga

b. Bagian dispensing/racik, untuk racikan dengan rata-rata waktu 18 menit 52 detik sedangkan untuk nonracikan dengan waktu 11 menit 19 detik. Hal-hal yang dilakukan pada bagian ini adalah:

1. Obat disiapkan sesuai dengan permintaan resep dokter

2. Obat dimasukan ke dalam kemasan dan diberi etiket

c. Bagian penyerahan obat, untuk racikan dengan rata-rata waktu 11 menit 50 detik sedangkan nonracikan dengan waktu 8 menit 19 detik. Hal-hal yang dilakukan adalah:

1. Sebelum diserahkan obat diperiksa kembali oleh petugas penyerahan obat

2. Penagihan harga obat dan pembayaran di kasir

3. Obat diserahkan kepada pasien disertai informasi pasien dan informasi obat sesuai dengan SPO penyerahan obat.

\section{c. Kelengkapan Komponen Informasi Obat yang Diberikan}

Pelayanan Informasi Obat kepada pasien (PIO) merupakan salah satu dari 11 komponen pelayanan farmasi klinis yang wajib dilakukan secara proporsional dan
Tabel 3 menunjukkan rata-rata waktu yang dibutuhkan untuk proses penyediaan obat. Rata-rata waktu keseluruhan proses penyediaan obat dibedakan menjadi resep racikan dan nonracikan. Rata-rata waktu penyediaan obat untuk resep racikan 39,48 menit, sedangkan untuk resep non-racikan 28,45 menit.

Berdasarkan pengamatan, lamanya waktu penyediaan obat terjadi karena beberapa faktor antara lain:

1. Kurangnya jumlah tenaga kerja akan memperlama dispensing time. Sementara itu beban volume pekerjaan semakin bertambah terlebih pada jam kunjungan tinggi (pada shift I), sehingga perlu adanya penambahan jumlah karyawan.

2. Waktu penyediaan obat ini juga dipengaruhi oleh lamanya resep tertumpuk di tempat penerimaan resep. Resep-resep yang masuk di IFRS juga akan menumpuk pada jam-jam 10.00 karena praktek dokter di tiap poliklinik yang seharusnya buka pada jam 08.0012.00 baru mulai buka jam 08.30, sehingga menyebabkan pasien yang akan melakukan pemeriksaan kesehatan menjadi menumpuk begitupula dengan resep-resep yang masuk ke IFRS.

Lamanya waktu penyediaan obat dapat mempengaruhi kepuasan pasien atas pelayanan yang diberikan oleh IFRS.

komprehensif di IFRS. Maksudnya adalah untuk meningkatkan outcome terapi dan meminimalkan resiko terjadinya efek samping karena obat untuk tujuan keselamatan pasien (patient safety) sehingga kualitas pasien terjamin. 
Pelayanan informasi obat yang merupakan kegiatan penyediaan dan pemberian informasi, rekomendasi obat yang independen, akurat, tidak bias, terkini dan komprehensif yang dilakukan oleh apoteker kepada dokter, perawat dan profesi kesehatan lainnya serta pasien dan pihak lain yang membutuhkannya sesuai dengan tujuan PIO (Kemenkes, 2016).

Tabel 4. Kelengkapan Komponen Informasi Obat bagi Pasien

\begin{tabular}{|c|c|c|c|}
\hline No. & $\begin{array}{l}\text { Materi Informasi yang } \\
\text { diberikan pada pasien }\end{array}$ & $\begin{array}{c}\text { Pasien yang } \\
\text { Diberi } \\
\text { Informasi } \\
\end{array}$ & Persentase \\
\hline 1 & Nama Obat & 60 & $60 \%$ \\
\hline 2 & Khasiat Obat/Indikasi & 0 & 0 \\
\hline 3 & Kontra Indikasi & 0 & 0 \\
\hline 4 & Dosis Pemakaian Obat & 11 & $11 \%$ \\
\hline 5 & Cara Pemakaian Obat & 15 & $15 \%$ \\
\hline 6 & Waktu Pemakaian Obat & 41 & $41 \%$ \\
\hline 7 & Aturan Pakai & 100 & $100 \%$ \\
\hline 8 & Lama Pemakaian & 50 & $50 \%$ \\
\hline 9 & $\begin{array}{l}\text { Makanan/Minuman yang } \\
\text { Harus Dibatasi }\end{array}$ & 0 & 0 \\
\hline 10 & $\begin{array}{l}\text { Aktivitas yang Harus } \\
\text { Dibatasi }\end{array}$ & 0 & 0 \\
\hline 11 & $\begin{array}{l}\text { Cara Penyimpanan yang } \\
\text { Benar }\end{array}$ & 0 & 0 \\
\hline 12 & $\begin{array}{l}\text { Cara Pembuangan yang } \\
\text { Benar }\end{array}$ & 0 & 0 \\
\hline
\end{tabular}

Penelitian menunjukkan bahwa belum ada pasien yang menerima informasi obat yang seseuai dengan Kepmenkes RI 2016 tentang Standar Pelayanan Farmasi di Rumah Sakit. Tabel 4 menunjukkan bahwa materi informasi yang sering diberikan pada pasien yaitu aturan pakai obat (100\%). Pemberian informasi obat yang dilakukan terhadap pasien yang mendapatkan resep khusus seperti pasien dengan penyakit tubercollocis, asma, diabetes dan cara pemakaian obat untuk pasien suppositoria, mata dan telinga.

Informasi obat yang tidak lengkap diberikan terjadi dikarenakan petugas yang menyerahkan obat merasa bahwa pasien telah diberikan informasi dari dokter, sehingga tidak perlu diberi informasi lagi selain itu keterbatasan waktu yang disebabkan banyaknya resep yang menumpuk pada jam sibuk yang menuntut untuk secepatnya memberikan pelayanan agar pasien tidak menunggu lama, dan juga karena pasien menjalani terapi rawat jalan dalam waktu yang cukup lama sehingga pasien sudah mengerti penggunaan obat.

\section{KESIMPULAN}

Kesimpulan yang didapat bahwa kinerja IFRS Liun Kendage Tahuna yang menggunakan metode $B S C$ dengan dua 
PHARMACONJurnal IImiah Farmasi - UNSRAT Vol. 9 No. 1 FEBRUARI 2020 ISSN $2302-2493$

perspektif menunjukkan kinerja yang cukup baik. Tetapi masih perlu adanya perbaikan dalam dispensing time, pengendalian persediaan obat dan pelayanan informasi obat.

\section{DAFTAR PUSTAKA}

Kemenkes RI. Peraturan Menteri Kesehatan Republik Indonesia Nomor 72 Tahun 2016 tentang Standar Pelayanan Farmasi di Rumah Sakit. Jakarta

Liando, H. S., Saerang, D. P. E., Elim. I. 2014. Analisis Kinerja Keuangan Pemerintah Kabupaten Kepulauan Sangihe Menggunakan Metode Value for Money. Jurnal EMBA. 2 : (3), 1686-1694

Mahmudi. 2005. Manajemen Kinerja Sektor Publik. UPP AMP YKPN, Yogyakarta.

Riduwan, Akdon. 2005. Rumus dan Data dalam Aplikasi Statistik. Alfabeta, Bandung

Rikomah, S. E. 2017. Farmasi Rumah Sakit. Deepublish, Yogyakarta.

Satibi, Fudholi, A., Kusnanto, H., dan Jogiyanto. 2011. Evaluasi Kinerja Instalasi Farmasi RSUD Kota Yogyakarta dengan Pendekatan Balanced Scorecard. Majalah Farmaseutik. 7 : (3), 77-85.

Siregar,C.J.P., Amalia, L .2003. Farmasi Rumah Sakit. Buku Kedokteran EGC, Jakarta

\section{SARAN}

Rumah Sakit diharapkan dapat melakukan penambahan SDM dan penelitian lebih lanjut tentang $B S C$ dengan dua perspektif lainnya yaitu perspektif customer, perspektif pembelajaran dan pertumbuhan. 